\section{Resolution of Type IV Hypersensitivity After Bone Marrow Transplantation}

Lázaro $\mathrm{M}^{1}$, Vázquez L $\mathrm{L}^{2,3}$, Laffond $\mathrm{E}^{3}$, Moreno $\mathrm{E}^{1,3,4}$, Macias EM ${ }^{1,3}$, Dávila I ${ }^{1,3,4}$

${ }^{1}$ Allergy Service, University Hospital of Salamanca, Salamanca, Spain

${ }^{2}$ Hematology Service, University Hospital, Salamanca, Spain

${ }^{3}$ Biomedical Research Institute, Salamanca, Spain

${ }^{4}$ Department of Biomedical and Diagnostic Sciences, Faculty of

Medicine, University of Salamanca, Salamanca, Spain

J Investig Allergol Clin Immunol 2018; Vol. 28(3): 190

doi: 10.18176/jiaci.0226

Key words: Contact dermatitis. Transplant. Resolution of hypersensitivity.

Palabras clave: Dermatitis de contacto. Trasplante. Desaparición de la hipersensibilidad.

Transfer of autoimmune, IgE-mediated type IV hypersensitivity has been reported after bone marrow transplantation [1-3]. Nevertheless, remission of allergic diseases after bone marrow transplantation has rarely been described [4]. We report a case of allergic contact dermatitis (ACD) that resolved after allogeneic hematopoietic stem cell transplantation (HSCT).

In 2006, a 41-year-old woman with acute myeloid leukemia (M5 subtype) underwent HSCT from an HLA-matched donor with a conditioning regimen based on thymoglobulin and cyclophosphamide. The patient achieved complete chimerism after the transplant. Since she had previously developed severe eczema upon contact with metallic earrings or watches, she avoided contact with such objects. No patch tests were performed before HSCT. After HSCT, she observed that she no longer developed lesions upon contact with the same metal objects that had previously produced the eczematous lesions. Patch testing with a standard battery of contact allergens including nickel, cobalt, and chrome (T.R.U.E. TEST, SmartPractice Denmark ApS) was negative at D2-D4. During an 8-year follow-up period, she did not develop eczema despite regular use of costume jewelry.

We present a case of resolution of ACD after HSCT. Our findings are limited by the absence of patch testing before HSCT and by the fact that the diagnosis of nickel allergy was based on a very highly suggestive clinical history. Nevertheless, the clinical picture points to resolution of nickel ACD, as the patient was able to wear metallic costume jewelry several months after transplantation. Resolution of type I hypersensitivity disease has been infrequently described [4], although, to our knowledge, the disappearance of type IV hypersensitivity has not been reported. A possible underlying mechanism of resolution could be the replacement of recipient hematolymphoid cells by nonallergic donor cells. In addition, immunosuppressive therapy (cyclosporine A) could have accounted for resolution, although this mechanism did not seem to be involved, as the patient had not developed metal-induced contact dermatitis during the 8 years after discontinuation of immunosuppressive therapy. Another possibility could be spontaneous remission of nickel allergy, although this is extremely infrequent. Thus, Patriarca et al [5] observed that immediate positive skin tests to ß-lactams became negative in $58.3 \%$ of type I allergic patients, but only in $6.7 \%$ of those with positive $\beta$-lactam patch test results. To further clarify this point, more allergic patients receiving BMT from nonallergic donors and controls should be studied.

In conclusion, we report a case of resolution of type IV hypersensitivity after bone marrow transplantation.

Funding

The authors declare that no funding was received for the present study.

Conflicts of Interest

The authors declare that they have no conflicts of interest.

\section{References}

1. Daikeler T, Tyndall A. Autoimmunity following haematopoietic stem-cell transplantation. Best Pract Res Clin Haematol. 2007;20:349-60.

2. Lázaro $M$, Vázquez L, Munoz-Bellido FJ, Gracia M, ArribaMendez S, Dávila I. Reproduction of the atopic march in and adult after allogeneic bone marrow transplantation from an atopic sibling. Ann Allergy Asthma Immunol. 2017;119:190-1.

3. Olaguibel J, Almodovar A, Giner A, Serrano J, Martinez J, Basomba A. Passive transfer of contact sensitivity to colophony as a complication of an allogenic bone-marrow transplant. Contact Dermatitis. 1989;20:182-4.

4. Hourihane JO, Rhodes HL, Jones AM, Veys P, Connett GL. Resolution of peanut allergy following bone marrow transplantation for primary immunodeficiency. Allergy. 2005;60:536-7.

5. Patriarca G, Schiavino D, Nucera E, Milani A. Positive allergological tests may turn negative with no further exposure to the specific allergen: a long term, prospective, follow-up study in patients allergic to penicillin. Invest Allergol Clin Immunol. 1996;6:162-5.

I Manuscript accepted for publication October 5, 2017; accepted for publication January 4, 2018.

Milagros Lázaro Sastre Calle Astorga, 21-25, Esc 2, 2º 37006 Salamanca Spain

E-mail: lazaro@alergoasma.es 